\title{
26 Research Square \\ Eggs With Trilobite Larvae in a Cambrian Community. Modeling the Hydrodynamics
}

\section{Tian Lan}

Guizhou University

\section{Yuanlong Zhao}

Guizhou University

Jorge Esteve

Universidad de los Andes

\section{Fangchen Zhao}

Nanjing Institute of Geology and Palaeontology and Centre for Excellence in Life and Palaeo-

environment

\section{Cong Li}

Guizhou University

Pedro Martinez ( $\sim$ Pedro.martinez@ub.edu )

Universitat de Barcelona

\section{Research Article}

Keywords: egg clusters, computational fluid dynamics, Kaili Biota, Wuliuan stage

Posted Date: May 28th, 2021

DOl: https://doi.org/10.21203/rs.3.rs-558709/v1

License: (1) (1) This work is licensed under a Creative Commons Attribution 4.0 International License.

Read Full License 


\section{Abstract}

Background: Reproductive behaviors include mating, pregnancy, birth, and ulterior brood care. Fossil records (eggs, nests, etc.) provide a glimpse into the reproductive sequences of ancient animals. Here, we show putative trilobite egg clusters from the middle Cambrian (Miaolingian, Wuliuan Stage) that were found in the Kaili Formation, South China. The arrangement of these egg clusters would ensure efficient oxygen diffusion from the water into cells.

Results: We applied a computational fluid mechanics simulation method to understand the behavior of Kaili trilobite eggs in Cambrian seawater under different flow patterns. The drag force and lift force load on the eggs increased rapidly when current speeds exceeded $0.2 \mathrm{~m} / \mathrm{s}$. Moreover, the drag coefficient of the single egg model was 1.8-2 times larger than that of each egg in the egg cluster model. The trilobite larva within the egg cluster (ca. $0.5 \mathrm{~mm}$ in size) are smaller than the eggs (ca. $0.6 \mathrm{~mm}$ ), which indicates that they had recently hatched.

Conclusions: We suggest that not all trilobites had an unmineralized preliminary stage in their ontogeny and that some protaspis shield may have been formed before hatching. Moreover, we hypothesize that aquatic animals can use egg clustering to effectively reduce the effects of drag and lift forces from the surrounding water.

\section{Introduction}

The fossilized eggs of aquatic animals have been found from all periods of the evolutionary history of metazoans (Donoghue et al., 2006). Oocytes, dividing embryos, and pre-hatching larvae from cnidarians and Markuelia worms have been collected from as early as the Cambrian period (Bengtson and Yue, 1997; Zhang et al., 2011). The evolution of lineages depends on the incorporation of novelties (genetic, morphological, or behavioral) that increase their ecological fitness. Some of these key innovations (e.g., the bivalved carapace) played a key role in the early evolution of parental care in our group of interest, the Arthropoda (Caron et al., 2016). However, our knowledge of the reproductive behavior of Cambrian animals with no parental care for their offspring remains relatively poor. Fossil eggs show various modes of preservation: phosphatization (Zhang and Pratt, 1994), pyritization (Siveter et al., 2014; Hegna et al., 2017; Bernárdez et al., 2019), and preservation as carbonaceous clay minerals (Caron et al., 2016; Gueriau et al., 2016) or silicon components (Lin et al., 2006; Yin et al., 2006). Notably, in any study of fossil embryos, distinguishing between abiotic and biological features may be difficult since some features result from diagenetic alteration. For instance, it is known that silicon components, relevant to our studied specimens (see below) have self-organization behavior under high alkalinity $(\mathrm{pH}>10)$ conditions (García-Ruiz et al., 2014) giving rise to structures that could complicate the interpretation of fossil affinities; however, such conditions are still incompatible with soft-bodied fossil formation. In fact, under conditions with a $\mathrm{pH}>10$, the unmineralized tissues of animal bodies would rapidly dissolve. Moreover, most invertebrate egg fossils appear flattened (Gueriau et al., 2016) or semi-solid (e.g., Hegna et al., 2017) as the result of different fossilization processes. In this study, we report the discovery of 
silicon spheres that are unlikely to be ooids or coprolites (Lin et al., 2006). This preservation of silicon eggs as 3D spheres (Lin et al., 2006) suggests a rapid fossilization process that occurred before the eggs were buried. Such a rapid fossilization process may have been favored in the silica-rich oceans where the Kaili Biota lived (Tarhan et al., 2016).

Trilobites are thought to have reproduced sexually, as do nearly all arthropods today. Pyritized eggs associated with Ordovician trilobites (e.g. Triarthrus) have been reported in previous studies (Hegna et al., 2017). However, whether all trilobites had an unmineralized preliminary stage in their ontogeny after hatching and whether some protaspis shield (protaspis = larva) formed before hatching remain disputed matters. Moreover, physiological aspects should have imposed limitations to the brooding systems and egg/egg-mass architectures. In this context, it is important to emphasize that the environmental oxygen levels are one of the major constraints affecting the metabolism of marine invertebrates, especially during the fertilization/deposition stages. Two relevant facts: the oxygen consumption of brooding females increases throughout embryonic development (Baeza et al., 2002) and the size and organization of egg masses regulate the diffusion of oxygen from water (i.e., the environment) to their center. Modelling the behavior of egg masses, thus, necessitates an accurate incorporation of those, structural and environmental, factors in the simulation.

All the changes a dead body is subject to prior to fossilization may lead to alterations in size and shape of specimen, which might be mistaken for pseudo artifacts. These processes (taphonomic) without doubt lead to a stepwise loss of information about the formerly living being and this needs to be taken into account when interpreting fossil findings. For instance, taphonomic experiments involving aquatic invertebrate embryos showed that the cell contents begin to homogenize into amorphous organic matter after weeks of treatment (Gostling et al., 2008). In a well-studied example, sea urchin embryos undergo a process of autolysis that involves cytoplasmic lipid fusion and the filling of the egg envelope (Raff et al., 2006). Moreover, lipid drops have been observed in the embryo-like fossils of the Doushantuo Formation (Raff et al., 2008) though they haven't been observed in the fossil record thereafter. The relevance of these preservation processes has impelled us to investigate how taphonomic factors may impact our egg mass interpretations.

To ensure hatching success, eggs must survive the physical conditions of their environments. To complete our description of the trilobite eggs we carried out hydrodynamic simulations to estimate the hydrodynamic properties of these extinct aquatic invertebrate eggs. The final aim was to have a more accurate view of how they behaved in Cambrian waters (an aspect few times contemplated in the bibliography).

Thus, we used in the study presented here the tools of comparative anatomy, software simulation, and decay experimentation to gain insights into the biological affinity, hydrodynamic properties, and taphonomy sequences of Cambrian trilobite egg clusters.

\section{Materials And Methods}




\subsection{Microstructure examinations}

More than 100 egg fossil clusters were collected from a 2-m thick layer in the upper part (Oryctocephalus indicus zone) of the Kaili Formation (Wuliuan Stage, $505 \mathrm{ma})$; located in Jianhe County $\left(108.390^{\circ} \mathrm{E}\right.$, $27.691^{\circ} \mathrm{N}$ ), Guizhou, China. The mudstone host specimens are housed at the Guizhou Research Center for Palaeobiology (GRCP), Guizhou University. Microstructure and element distribution of the fossils were analyzed using Leica M205C and DVM6 stereo and digital microscopes plus a COXEM EM-30 scanning electron microscope (SEM). The energy-dispersive spectrometry analysis (EDSA) involved using the COXEM EM-30 SEM with a spot size of $100 \mathrm{~nm}$. Selected specimens were scanned using a Micro-CT Zeiss Xradia 520 system at the Nanjing Institute of Geology and Paleontology, the Chinese Academy of Sciences (NIGPAS), and Yunnan University. A $50 \mathrm{kV}$ operating voltage of the X-ray tube was used with a thin filter to reduce beam-hardening artifacts. The resulting data (in the form of a suite of TIFF images) were processed using the software Drishti (v. 2.4), which is regularly used for the three-dimensional analysis of fossils.

\subsection{Taphonomic analysis of eggs}

An experimental taphonomy study of the brine shrimp Artemia shows the embryo shrinks within the cyst and cellular detail of breaks down as lipid droplets (Gostling 2009). Here we use Xenopus laevis, an aquatic animal with a transparent embryo, as a reference model to understand the taphonomic effects on embryos. The embryo size was $0.6-0.7 \mathrm{~mm}$, which is approximately the same as that of the Kaili sphere fossils. The decay stages of eggs were compared to those of the putatively decaying sphere fossils (Figure $3 \mathrm{~J}$ ). These experiments were performed at the Max-Planck "Neuro-development and Evolution" laboratory at the Kunming Institute of Zoology (China). In the experimental group 100 Xenopus laevis embryos were transferred to water with $5 \%$ alcohol for $1 \mathrm{~h}$. These loosely aggregated, developmentally arrested embryos (Figure S1D) were left then to autolyze in water at $25^{\circ} \mathrm{C}$ for 1 week. The water depth of the embryo containers was kept at $20 \mathrm{~mm}$. In parallel, a control group containing 100 Xenopus laevis embryos was left, undisturbed, to develop at $25^{\circ} \mathrm{C}$ in fluoride-free water (standard conditions).

\subsection{Fluid dynamic behavior of fossil embryos}

Computational fluid dynamic (CFD) simulations of the fossil embryo models (see Rahman et al., 2015 for an example) were conducted using the COMSOL Multiphysics 5.4 software. The fluid properties of seawater were introduced as parameters into the model: i.e., $t=26^{\circ} \mathrm{C}$, where $\rho$ is density $\left(\mathrm{kg} / \mathrm{m}^{3}\right) 1055.1$ and $\mu$ is Kinematic viscosity $(\mathrm{Pa} * \mathrm{~s}) 9.98 \times 10^{-4}$. The nature of the COMSOL methodology involves using finite-element analysis to solve constituent equations, meaning that the study object and its surroundings are divided into meshes (elements) that allow the system to be easily computable. The physics-based normal mesh consisted of free tetrahedral elements with a boundary layer mesh component; laminar and turbulent flow models were introduced in the simulations. A stationary solver was used to compute 
steady-state flow patterns. Sensitivity tests (change of mesh size) were performed to ensure the convergence of solutions (Figure S2).

Drag force is dominated by the surface drag in a laminar flow pattern. The surface drag per unit of depth is measured as $\mu \mathrm{UL} / \mathrm{B}$ (Gazzola et al., 2014), where $U$ is the fluid speed, $\mu$ is the fluid viscosity, $L$ is the object length, $B$ is the thickness of the boundary layer $\left(B \sim L R e^{-1 / 2}\right)$ (Landau, 1959), and $R e$ is the Reynolds number. Integrating those parameters in a single equation we determine the drag force $\left(F_{d}\right)$ as:

$F_{d}=\mu U \operatorname{Re}^{1 / 2}(1)$

Drag force starts to be dominated by the pressure drag (from eddying motions that are set up in the fluid by the passage of the body) in a turbulent flow pattern:

$F_{d=} \mu U R e(2)$

The built-in function of COMSOL to calculate the object drag force within the fluid field is based on the surface integration of the force on the object. The drag coefficient $\mathrm{Cd}$ is equal to the drag $\mathrm{D}$ divided by the quantity density $r$ times half the velocity $v$ squared times the reference area $A$ :

$\mathrm{Cd}=2 \mathrm{D} / \operatorname{Arv}^{2}(3)$

Hence, using the COMSOL software and the aforementioned fluid mechanical equations we have derived the physical properties of sphere fossil clusters from the Kaili Biota.

\section{Results}

\subsection{Fossil affinities and preservation}

Putative trilobite egg clusters and embryos from the middle Cambrian of the Kaili Formation are described here using different approaches. Morphologically, the outer layers of the fossil spheres are black in color and rich in silicon (Figure 1A, 2H).

By contrast, the inner core of the sphere is filled with high-density minerals (Figs. 1A2, 2C), which indicates that the outer layer and the inner core of the fossil are made up of different materials. The detected quadripartite spheres are reminiscent of blastomeres in an extant embryo (Figs. 1B, 2F). The presence of a sunken portion in the sphere suggests that the shell might have been flexible before fossilization (Fig. 2G).

Inorganic concretions are not rare in sediments. The tomographic image of specimen GRCP 15020 (Fig. 1A2) shows different degrees of compaction of the spheres with some spheres collapsed into amorphous flattened material (Fig. 3J) suggesting that the spheres were elastic; this fact would exclude a priori an abiotic interpretation for these silicon spheres. The observed putative decay stages of the sphere fossils 
(Figs. 1A2, 3J) also indicate that when the outer layer was broken, the contents were released (Fig. 3) and this layer flattened (Figs. 1A, 2).

Two main variables characterize the morphology of the eggs: the degrees of asymmetry and ellipticity (Stoddard et al., 2017) on the one side and the size range and shape of the egg fossil clusters, with sizes varying in the range of Min diameter $=528 \mu \mathrm{m}$ and Max diameter $=757 \mu \mathrm{m}\left(d_{\text {mean }}=612 \mu \mathrm{m}, \mathrm{n}=50\right)$ in GRCP 15022 on the other. As some eggs are deformed, we chose to measure the egg with a roundish outline to exclude the impact of deformation. The large quantities of eggs found in the Kaili Biota samples (we collected more than 10,000 within 108 clusters) indicate that the egg-laying animal was potentially a dominant clade in this biota.

In fact, trilobites are highly abundant in the Kaili Biota. We have observed that the early hatching stage of trilobites is normally associated with egg clusters (e.g., GRCP 15022-GRCP 15024). The highly crowded clusters have an obvious shape (Figs. 1C-E), indicative that they are, at least, part of individual egg clutches. Based on our observations is unlikely that external trilobite larvae mixed with the eggs. Some trilobite larvae remained, most probably, at the deposition site (Schwimmer 2019) (Figs. 1E). The trilobite larvae within the egg cluster (Figs. 1C, E) (ca. $0.5 \mathrm{~mm}$ ) were slightly smaller than the egg (ca. $0.6 \mathrm{~mm}$ ), which most probably indicates that they had recently hatched. The round-shaped larvae, dark in color (the same color as the egg) (GRCP 15023), are interpreted here as pre-hatching trilobite larva (Figs. 1D, D1). Comparatively, the post-hatched larvae are light in color (Figs. 1C, E). In this context, GRCP 15023 would indicate that a protaspis shield may have formed before hatching.

The number of eggs in each cluster range from approximately 300 in GRCP 15020 to 400 in GRCP 15022. We also found eggs on the substrate sheet with densely packed micro-protrusions (Figs. 2A, B). The eggs and micro-protrusions are made up of similar elements (Figs. $2 \mathrm{H}, \mathrm{I}$ ), the eggs may be associated with the trilobites (Figs. 2A). Additionally, we observed the presence of some cracked eggs that were empty inside (Fig. 2D).

\subsection{Taphonomy testing}

Most of the extant animal eggs for any single species fall into a narrow range, irrespective of an incredible diversity of shapes present across different animals for any species. However, the spheres' sizes, within individual clusters, are remarkably varied in some of the fossil specimens analyzed here (e.g., Fig. 3, GRCP 15029). Since it has been observed in some developmentally arrested embryos (e.g. the Xenopus laevis embryos tested here as living surrogates) that soft tissues decay via a process that leads to the liberation of white homogeneous yolky droplets (Figs. 3A-D; see also Raff et al, 2006 for other embryos), we speculated with the possibility that this could happen also in fossilized specimens. In fact, the sizes of our small fossil spheres is similar to the size of the homogeneous droplets observed in decaying $X$. laevis embryos. Thus, we interpret small fossil spheres (Fig. 3J) as homogenized drops released by the decayed egg masses. Moreover, the amount of well-preserved fossil embryos found in the 
biota suggest that they became fossilized in a reducing environment that blocked autolysis shortly after death.

\subsection{Computational fluid dynamic analysis of the egg and egg cluster models}

The behavior of the eggs in their liquid environment was simulated using CFD models. The diameter $(\mathrm{L})$ of the egg model was set at $0.6 \mathrm{~mm}$, which is approximately the same as the average size of the observed fossil spheres. The egg cluster model was based on specimen GRCP 15004 (Fig. 2E). To simulate the current speed at the water-sediment interface in the Kaili Biota (slope face), we used several modern references: 1$)$ the maximum near-bottom water flow speed $(<0.5 \mathrm{~m} / \mathrm{s})$ can be inferred for finegrained sediment environments (Kuijpers et al., 2016); 2) fast near-bottom currents occur over the slope above the level of $0.2 \mathrm{~m} / \mathrm{s}$ (Csanady et al., 1988).

A 6-mm sublayer was found in the horizontal flow profiles obtained at the water-sediment interface in 200-m deep water on the Oregon continental shelf (Caldwell and Chriss, 1979). In this sublayer, the current speed drops. In the case of the benthic biota of Kaili, which live on the continental shelf (Lan 2018), $0.01,0.03,0.05,0.25$, and $0.5 \mathrm{~m} / \mathrm{s}$ were chosen for our calculations (Figs. $4-6$ ). $R e=2300$ is the critical Reynold's number, which marks the switch from a laminar to a turbulent flow pattern. The calculated Reynolds number $(\mathrm{Re}=\rho \mathrm{LL} / \mu)\left(10^{2}-10^{4}\right)$ of the egg cluster suggests that the cluster experienced a transition from a laminar flow pattern $(\mathrm{Re}<2300)$ (Figs. 5A, 6B) to a turbulent flow pattern ( $R e>2300$ ) (Figure 5B, 5C, 6A) when the current speed increased.

The CFD simulations provided some key insights into the behavior of fossilized eggs and egg clusters within fluids. First, the results of the pressure field on the 3D model of the egg cluster showed that the pressure field affecting the eggs within the cluster was nearly isotropic under the lower fluid speed situation $(0.05 \mathrm{~m} / \mathrm{s})(\mathrm{Fig} .4 \mathrm{~A})$. As the fluid speed rose $(0.25-0.5 \mathrm{~m} / \mathrm{s})$, a pressure gradient was established, and thus experienced, from the anterior to posterior part (facing the current) of the egg cluster (Figs. 4B-D).

The 2D egg cluster model showed that the tail vortex of spheres clustered at higher fluid speeds $(0.5 \mathrm{~m} / \mathrm{s})$ (Figs. 5C, 6A) and was much stronger than that experienced at low fluid speeds $(0.03,0.05 \mathrm{~m} / \mathrm{s})$ (Figs. 5B, $6 \mathrm{~B})$. The tail vortex disappeared when the fluid speed was reduced to $0.01 \mathrm{~m} / \mathrm{s}$ (Fig. $5 \mathrm{~A}$ ).

Drag forces depend on the Reynolds number, so when the $\operatorname{Re}(\operatorname{Re}=\rho \mathrm{L} / \mu)$ of the egg was $<1$, drag force was governed by the surface drag. Conversely, drag force started to be dominated by the pressure drag for eggs at higher Reynolds numbers $(\operatorname{Re}>1)$. Under these conditions, the fluid speed dropped rapidly around the egg cluster (Figs. 4-6), thus generating a smaller drag force load on the central eggs than on the marginal ones.

To understand how drag and lift forces affect single or grouped eggs, we compared forces on one egg (in a cluster or isolated) at different current speeds by using COMSOL 5.4 software. The results indicate that the forces experienced grow much slower for the egg cluster model than for the single egg model (Figs. 
7A, 7C) when the current speed increased. The drag coefficient of the single egg model is $0.8-1$ times larger than that of each egg in the egg cluster model (Fig. 7B). These different simulations lead us to conclude that, notably, clustered eggs reduce the drag and lift forces experienced by each egg within the current, thus providing a quantitative physical explanation for the clustering of eggs in the trilobites.

\section{Discussion}

Waptia arthropods (a stem-group pancrustacean) of the Cambrian period have relatively advanced neural systems (Strausfeld, 2016), which suggests the emergence of complex animal behaviors such as parenting. The diversification of brood care in early, free-swimming waptiids has been recorded by various authors (Caron et al., 2016; Ou et al., 2020). However, egg-laying behaviors in the early clades, without brood care, remain poorly understood. Since physical modeling allows us to simulate the effects of environmental conditions in specimens in both present and past conditions, we applied some of those methodologies to assess the effects of various environments on Cambrian eggs.

The hydrodynamic simulations of egg cluster models show the tradeoff (Ou et al., 2020; Rahman. 2020) between oxygen availability and the stability/integrity of an egg as mediated by the turbulence of the surrounding media. Under low current speed conditions with minimal drag forces from the water, a cluster is more stable (higher integrity). However, since the oxygen level of the stagnant water is relatively low, we hypothesize that laying eggs in a more turbulent environment would increase the oxygen availability of the egg. Needless to say, a high-speed current would raise the risk of the egg cluster losing its structural integrity, so a compromise between speed and oxygen ability has to be reached. Under conditions where the drag and lift forces from the water are larger than the adhesion force of eggs to the substrate, the eggs will be swept away by the current. Thus, clustering eggs is an effective solution for aquatic animals to reduce the effects of drag and lift forces from the surrounding water (Fig. 7A, C).

The above reasoning means that an adequate current speed for the survival of Cambrian trilobite egg masses needs to be incorporated. However, obtaining a precise estimation of the current speed of Kaili benthic biota requires some additional parameters (e.g., levels of oxygen consumption of the eggs, etc.), which we cannot determine from the fossils. Under a 6-mm sublayer in horizontal flow at the watersediment interface in $200 \mathrm{~m}$ deep water on the continental shelf where the Kaili benthic Biota lived, the speed of the current drops rapidly, the sublayer acts as a buffer to protect eggs from facing high current speeds.

In an ideal state (i.e., eggs are spheres of equal size), an egg within a cluster would contact 12 adjacent ones (Pfender and Ziegler, 2004). However, while obvious gaps exist among the eggs in sample GRCP 15001 (Figure 2A), other eggs are present highly packed in samples such as GRCP 15002 (Figure 2C). There are disadvantages to individual eggs being part of highly packed groups (Torquato et al., 2000), the most important of which is that oxygen diffusion will not be as efficient as that experienced by an egg in a loosely packed pattern. Moreover, the sticky, non-rigid eggs do not pack like spherical solid grains in a column. For example, the spherical egg in GRCP 15002 (Figure 2C) has a clear polygonal outline, which 
decreases the oxygen diffusion space. There is a tradeoff of stability and oxygen diffusion within egg cluster.

To finalize, it important to stress that egg size and shape have evolved in response to the life history and ecology of different animals (Church et al., 2019; Moran et al., 2009). In particular, the origin of aquatic oviposition was significantly associated with the evolution of eggs with lower aspect ratios (i.e., the ratio of length to width; Church et al., 2019). In this study, we show that-as per most known Cambrian egg fossils - that these trilobite eggs were paraspherical (e.g., Zhang and Pratt, 1994).

\section{Conclusion}

In this study, no egg clusters were preserved in association with an adult fossil animal, which suggests that the parents of the eggs were not involved in brood care. This "drop and go" strategy may increase the risk of the eggs being consumed by the predators. Many animals using the so-called reproductive rstrategies (i.e., producing many offspring, each of which has a relatively low probability of surviving to adulthood) choose to spawn simultaneously, which reduces the possibility of individuals within the cluster being consumed by predators. The presence of a rich layer of egg fossils in the Kaili Formation is consistent with the use of synchronized spawning. Moreover, large egg masses as described here are in line with the hypothesis that trilobites lived in large colonial assemblies, again a good strategy for survival in environments with predators.

The diversification of laying strategies among brood care and non-brood care clades reveals that the Cambrian explosion not only embodied body plan innovation, but that sophisticated behavioral repertoires emerged within different clades in parallel with the origin and diversification of major phyla. Some of the key innovations in laying strategies might have helped animals to expand their living niches while also contributing to both morphotype diversification and the underlying patterns of development in embryos. Our study suggests that not all trilobites had an unmineralized preliminary stage in their posthatching ontogeny and that some protaspis shields may have formed before hatching. Using an array of observational and simulation tools provided us with new insights into the ecological conditions in which the fossil embryos lived.

\section{Declarations}

\section{Competing interests}

Not applicable

\section{Data accessibility}

All fossil specimens from the Kaili Formation are deposited in the collections of the Guizhou Research Center for Palaeobiology, Guizhou University, Guizhou, China. 
Authors' contributions

T.L. and Y. L. Z. conceived the study. T. L. and C. L. ran the CFD simulation. T. L. wrote the initial draft. T. L., P.M., J.E., and F. C. Z completed the final draft.

\section{Funding}

This research is supported by the National Natural Science Foundation of China (No. 41902003) and the Natural Science Foundation of Guizhou (No. 20171057). Pedro Martinez was supported by a grant from the Ministerio Ciencia e Innovación (No. PGC2018-094173-B-I00).

\section{Acknowledgments}

We thank Z. J. Yin of the Nanjing Institute of Geology and Palaeontology, Chinese Academy of Sciences (NIGPAS) as well as H. J. Mai of Yunnan University and F. Liu for the collection of Kaili Biota samples.

\section{References}

1. Autumn K, Liang Y A, Hsieh S T, et al. Adhesive force of a single gecko foot-hair. Nature, 2000, 405 (6787): 681.

2. Baeza, J. A., and Fernández, M. (2002). Active brood care in Cancer setosus (Crustacea: Decapoda): the relationship between female behaviour, embryo oxygen consumption and the cost of brooding. Functional Ecology, 16(2), 241-251.

3. Bengtson S, Yue Z. Fossilized metazoan embryos from the earliest Cambrian. Science, 1997, 277 (5332): 1645-1648.

4. Bernárdez, E., Esteve, J., Laibl, L., Rábano, I., and Gutiérrez-Marco, J. C. (2019). Early post-embryonic trilobite stages and possible eggs from the 'Túnel Ordovícico del Fabar'(Middle Ordovician, northwestern Spain). In Papers from the 6th International Conference on Trilobites and their Relatives (pp. 23-33). Chichester, UK: John Wiley and Sons, Ltd.

5. Corsi A K, Wightman B, Chalfie M. A transparent window into biology: a primer on Caenorhabditis elegans. Genetics, 2015, 200 (2): 387-407.

6. Caron J B, Vannier J. Waptia and the diversification of brood care in early arthropods. Current Biology, 2016, 26 (1): 69-74.

7. Church, S. H., Donoughe, S., de Medeiros, B. A., and Extavour, C. G. (2019). Insect egg size and shape evolve with ecology but not developmental rate. Nature, 571(7763), 58.

8. Caldwell, D. R., and Chriss, T. M. (1979). The viscous sublayer at the sea floor. Science, 205(4411), 1131-1132.

9. Csanady, G. T., Churchill, J. H., and Butman, B. (1988). Near-bottom currents over the continental slope in the Mid-Atlantic Bight. Continental Shelf Research, 8(5-7), 653-671. 
10. J. Crisp, in Biology and Systematics of Colonial Organisms, G. P. Larwood, B. R. Rosen, Eds. (Academic Press, New York, 1979), pp. 319-327.

11. Donoghue, P. C., Kouchinsky, A., Waloszek, D., Bengtson, S., Dong, X. P., Valkov, A. K.,and Repetski, J. E. (2006). Fossilized embryos are widespread but the record is temporally and taxonomically biased. Evolution and development, 8(2), 232-238.

12. Ehrlich, H., Rigby, J. K., Botting, J. P., Tsurkan, M. V., Werner, C., Schwille, P., ... and Vyalikh, D. V. (2013). Discovery of 505-million-year old chitin in the basal demosponge Vauxia gracilenta. Scientific reports, 3, 3497.

13. García-Ruiz JM, Nakouzi E, Kotopoulou E, et al. Biomimetic mineral self-organization from silicarich spring waters. Science Advances, 2017, 3 (3): e1602285.

14. Gazzola, M., Argentina, M., and Mahadevan, L. (2014). Scaling macroscopic aquatic locomotion. Nature Physics, 10(10), 758-761.

15. Gueriau P, Rabet N, Clément G, et al. A 365-million-year-old freshwater community reveals morphological and ecological stasis in branchiopod crustaceans. Current Biology, 2016, 26 (3): 383390.

16. Gorb S N. The design of the fly adhesive pad: distal tenent setae are adapted to the delivery of an adhesive secretion. Proceedings of the Royal Society of London B: Biological Sciences, 1998, 265 (1398): 747-752.

17. Gostling, N. J., Thomas, C. W., Greenwood, J. M., Dong, X., Bengtson, S., Raff, E. C., and Donoghue, P. C. (2008). Deciphering the fossil record of early bilaterian embryonic development in light of experimental taphonomy. Evolution and development, 10(3), 339-349.

18. Heyward AJ, Negri AP. Turbulence, cleavage, and the naked embryo: a case for coral clones. Science, 2012, 335 (6072): 1064-1064.

19. Hegna TA, Martin MJ, Darroch SAF. Pyritized in situ trilobite eggs from the Ordovician of New York (Lorraine Group): Implications for trilobite reproductive biology. Geology, 2017, 45 (3): 199-202.

20. Hong, S., 2011, Biology of horseshoe crabs, Tachypleus tridentalus : Xiamen University Press, Xiamen, China, $342 \mathrm{p}$.

21. Rahman, I. A., Darroch, S. A., Racicot, R. A., and Laflamme, M. (2015). Suspension feeding in the enigmatic Ediacaran organism Tribrachidium demonstrates complexity of Neoproterozoic ecosystems. Science Advances, 1(10), e1500800.

22. Kuijpers, A., and Nielsen, T. (2016). Near-bottom current speed maxima in North Atlantic contourite environments inferred from current-induced bedforms and other seabed evidence. Marine Geology, $378,230-236$.

23. Landau, L. D.and Lifshitz, E. M. Fluid Mechanics (PergamonPress,1959).

24. Lin JP, Scott AC, Li CW, et al. Silicified egg clusters from a Middle Cambrian Burgess Shale-type deposit, Guizhou, south China. Geology, 2006, 34 (12): 1037-1040. 
25. Ou, Q. , Vannier, J. , Yang, X. , Chen, A. , and Mayer, G. . (2020). Evolutionary trade-off in reproduction of cambrian arthropods. ence Advances, 6(18), 3376-3405.

26. Pfender F, Ziegler GM. Kissing numbers, sphere packings, and some unexpected proofs. NoticesAmerican Mathematical Society, 2004, 51: 873-883.

27. Raff, E. C., Villinski, J. T., Turner, F. R., Donoghue, P. C., and Raff, R. A. (2006). Experimental taphonomy shows the feasibility of fossil embryos. Proceedings of the National Academy of Sciences, 103 (15), 5846-5851.

28. Raff, E. C., Schollaert, K. L., Nelson, D. E., Donoghue, P. C., Thomas, C. W., Turner, F. R., and Stampanoni, M. (2008). Embryo fossilization is a biological process mediated by microbial biofilms. Proceedings of the National Academy of Sciences, 105(49)

29. Rahman, I. A. , O'Shea, J. , Lautenschlager, S. , \& Zamora, S. . (2020). Potential evolutionary trade-off between feeding and stability in cambrian cinctan echinoderms. Palaeontology.

30. Richter, S., and Scholtz, G. (2001). Phylogenetic analysis of the Malacostraca (Crustacea). Journal of Zoological Systematics and Evolutionary Research, 39, 113-136.

31. Sánchez-Villagra, M. (2012). Embryos in deep time: the rock record of biological development. Univ of California Press.

32. Siveter DJ, Tanaka G, Farrell ÚC, et al. Exceptionally preserved 450 - million - year - old Ordovician ostracods with brood care. Current Biology, 2014, 24 (7): 801-806.

33. Schwimmer, D. R., and Montante, W. M. (2019). A Cambrian meraspid cluster: evidence of trilobite egg deposition in a nest site. Palaios, 34(5), 254-260.

34. Schubert, J. K., Kidder, D. L., and Erwin, D. H. (1997). Silica-replaced fossils through the Phanerozoic. Geology, 25(11), 1031-1034.

35. Shen, C. , Clarkson, E. N. K. , Yang, J. , Lan, T. , Hou, J. B. , and Zhang, X. G. . (2014). Development and trunk segmentation of early instars of a ptychopariid trilobite from cambrian stage 5 of china. Scientific Reports, 4, 6970-6970.

36. Strathmann, R. R., and Chaffee, C. (1984). Constraints on egg masses. II. Effect of spacing, size, and number of eggs on ventilation of masses of embryos in jelly, adherent groups, or thin-walled capsules. Journal of Experimental Marine Biology and Ecology, 84(1), 85-93.

37. Strausfeld NJ. Waptia revisited: intimations of behaviors. Arthropod structure and development, 2016, 45 (2): 173-184.

38. Stoddard, M. C., Yong, E. H., Akkaynak, D., Sheard, C., Tobias, J. A., and Mahadevan, L. (2017). Avian egg shape: Form, function, and evolution. Science, 356(6344), 1249-1254.

39. Tarhan LG, Hood A, Droser ML, et al. Exceptional preservation of soft-bodied Ediacara Biota promoted by silica-rich oceans. Geology, 2016, 44 (11): 951-954.

40. Torquato S, Truskett TM, Debenedetti PG. Is random close packing of spheres well defined? Physical review letters, 2000, 84 (10): 2064. 
41. Waddy SL, Aiken DE, De Kleijn DPV. Control of growth and reproduction. Biology of the Lobster Homarus americanus, 1995: 217-266.

42. Yin, L., Zhu, M., Knoll, A. H., Yuan, X., Zhang, J., and Hu, J. (2007). Doushantuo embryos preserved inside diapause egg cysts. Nature, 446(7136), 661.

43. Zhang X G, Pratt B R. Middle Cambrian arthropod embryos with blastomeres. Science, 1994: 637637.

\section{Figures}

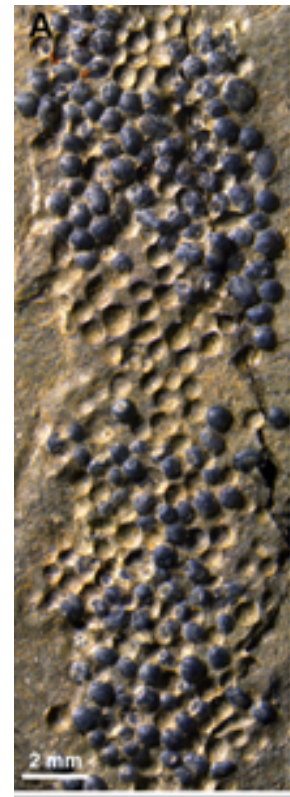

A2

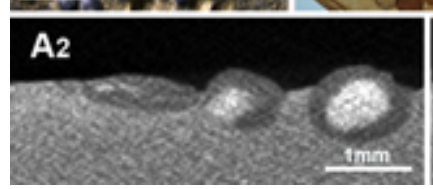

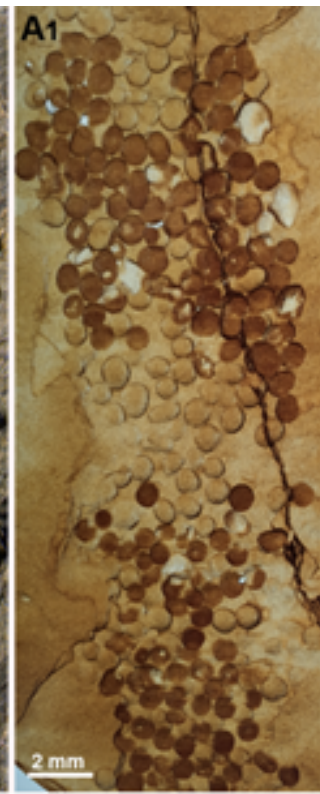

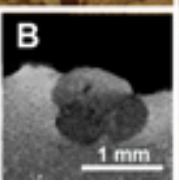

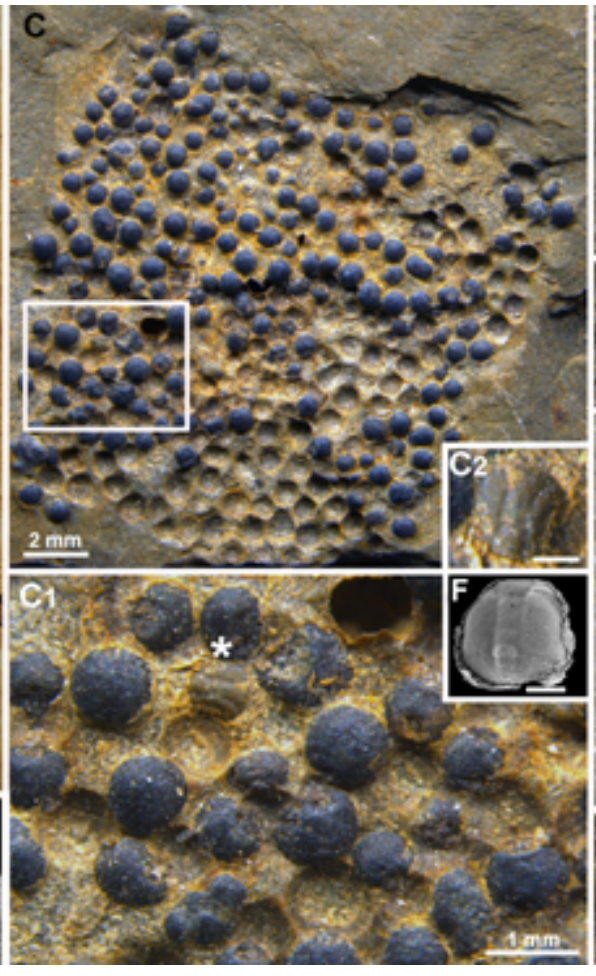

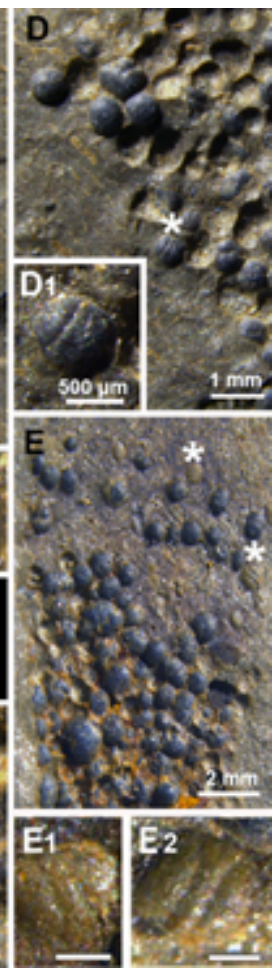

\section{Figure 1}

Egg cluster fossils from the Cambrian Biota (Wuliuan Stage). A『GRCP 15020, column showing an elongated egg cluster; A1, tomographic image of GRCP 15020; the smaller egg size in the lower part of the specimen might be due to postmortem shrink-age; A2, tomographic image of GRCP 15020, showing different degrees of compaction of the eggs; B, close-up of one egg in GRCP 15021; C, GRCP 15022, egg cluster containing a trilobite larva within it; $\mathrm{C} 1$, close-up of the white square area in $\mathrm{C}$ with the tri-lobite larva (under the asterisk); C2, higher magnification of the trilobite larva shown in C1. D, GRCP 15023, showing a pre-hatching trilobite larva (under the aster-isk); D1, higher magnification of the pre-hatching trilobite larva present in D. E, GRCP 15024, showing some of the early hatching larvae (under the asterisk) in associ-ation with a loosely formed egg cluster; E1 and E2, showing pre-hatching stages of a larva present in specimen GRCP 15024. F (inset in Fig C1), protaspis of a trilobite from the Wuliuan Stage of Guizhou (reprinted with permission from Fig. 4J of the Shen et al., 2014.), with an egg shell-like structure . Scale bar: C2, E1, E2: $200 \mu \mathrm{m}, \mathrm{F}, 100 \mu \mathrm{m}$. 

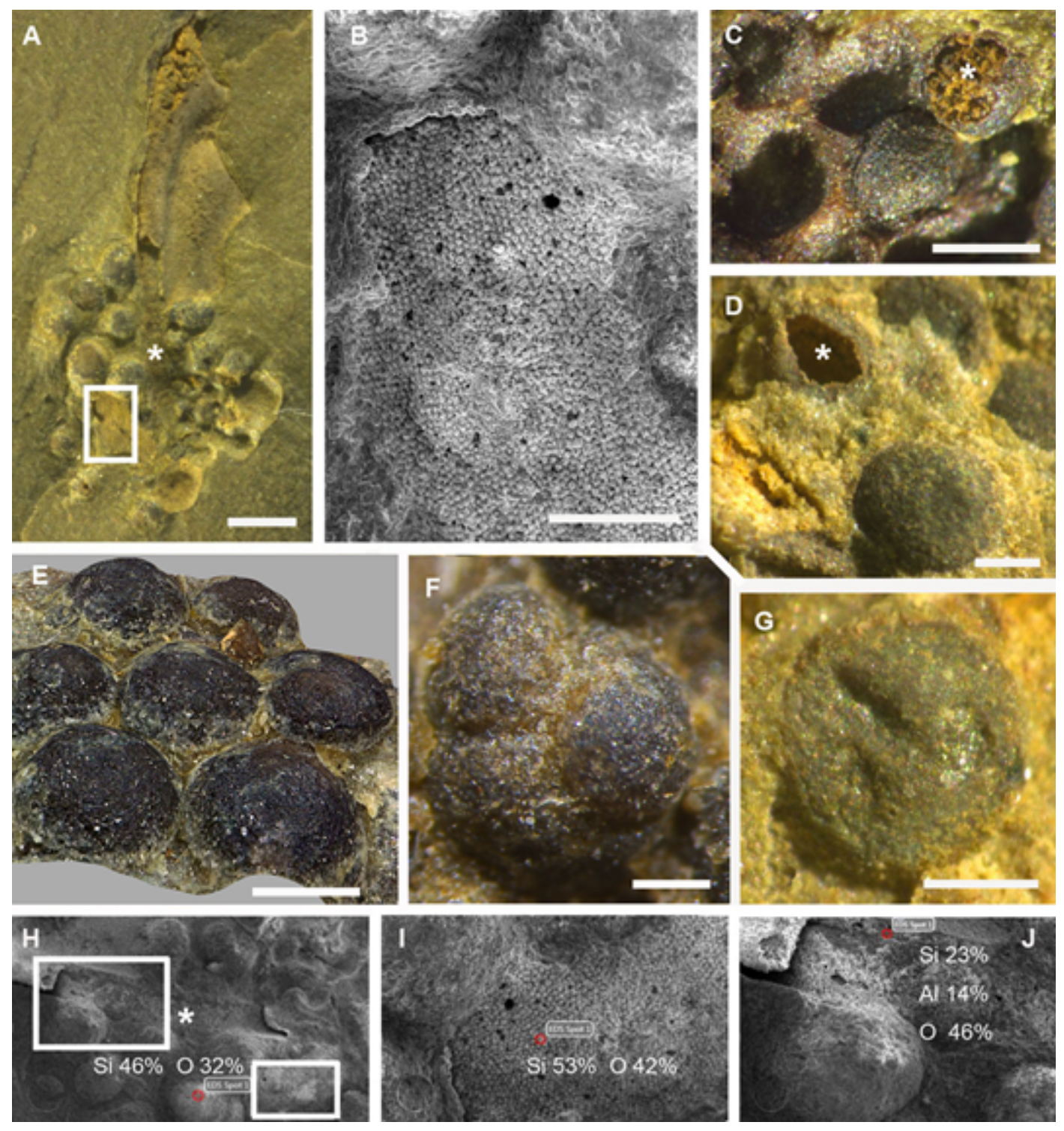

\section{Figure 2}

Egg cluster fossils of the Kaili Biota of Cambrian (Wuliuan Stage). A, An egg cluster attached to a trilobite fragment (GRCP 15001); $B$, close-up of the square frame in A, showing the sheet with micro protrusions; C, cracked egg filled with min-erals (GRCP 15002); D, empty cracked egg among other individuals (GRCP 15003); E, egg cluster sheet (GRCP 15004), showing a central egg in contact with 6 adjacent ones; $F$, putative blastomeres (GRCP 15005); $G$, an egg with a sunken section of the shell (GRCP 15006); H, energy-dispersive spectrometry analysis (EDSA) of the egg surface, showing how the sheet seems to be peeling; I, close-up view of the small square frame in H, EDSA on the egg cluster's substrate of specimen GRCP 15001; J, EDSA on the trilobite fragment shown in panel A. Scale bar: A, $2 \mathrm{~mm} ; \mathrm{B}, \mathrm{F}, 100 \mu \mathrm{m} ; \mathrm{C}, \mathrm{E}$ $300 \mu \mathrm{m} ; \mathrm{D}, \mathrm{G} 200 \mu \mathrm{m}$. Mineral composition in the $\mathrm{H}-\mathrm{J}$ panels given as percentages of mass. 


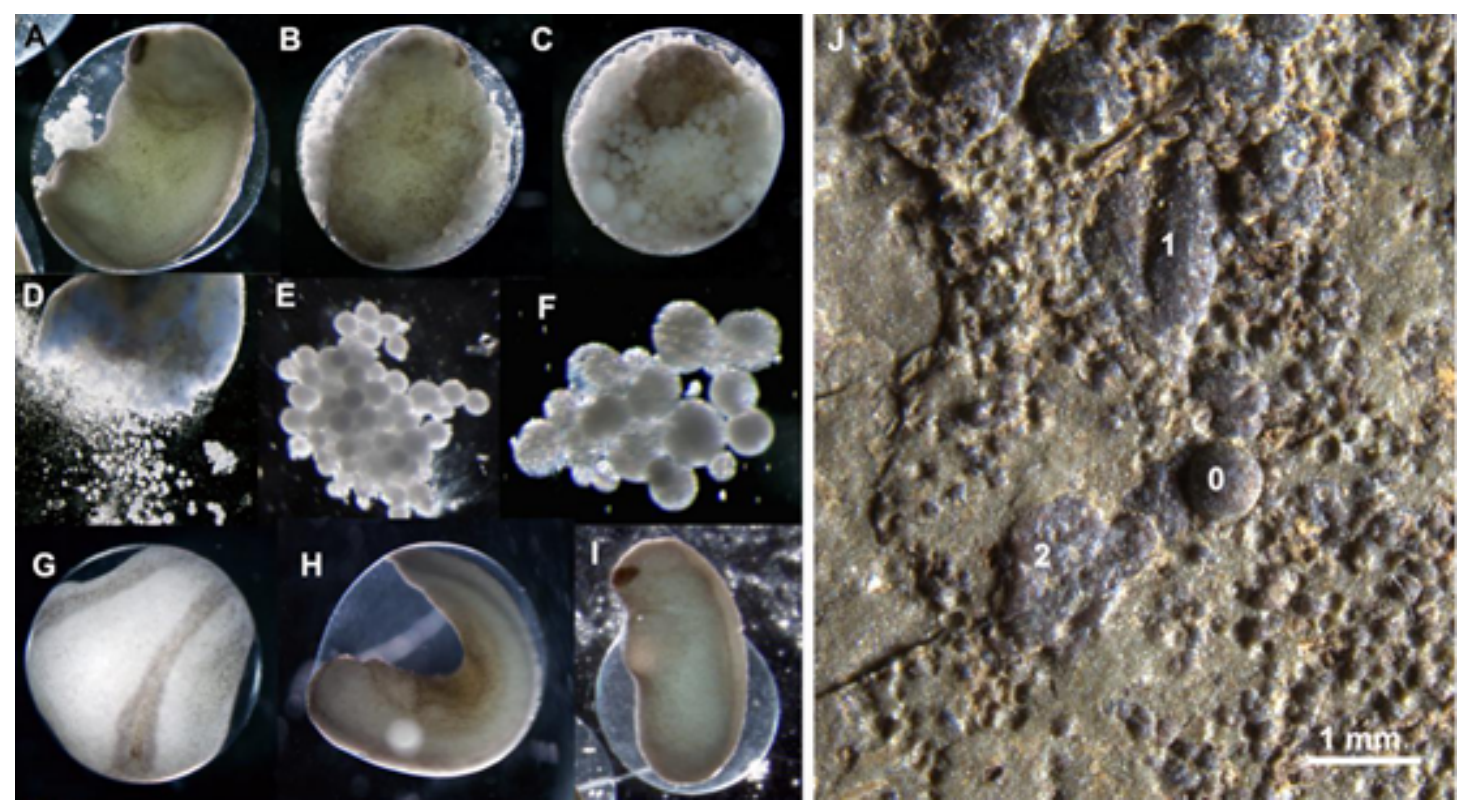

Figure 3

The development and decay sequence of the embryo of Xenopus laevis and the putative egg fossils of the Kaili Biota. A-D The decay sequence of a X. laevis embryo, showing soft tissue transfer to homogenized drop clusters. $D$, the homogenized drops in the clusters are released outside after the egg shell brakes; E-F, a close-up view of the gradual clustering of lipid drops outside the egg shell. G-I, a reference developmental sequence of $\mathrm{X}$. laevis embryos photographed over a similar period than the decay experiments. J. GRCP 15029, showing eggs at different decaying stages: 0 , the well-preserved egg; 1, a partly decayed egg; 2 a fully decayed egg. Droplets are released around the eggs.
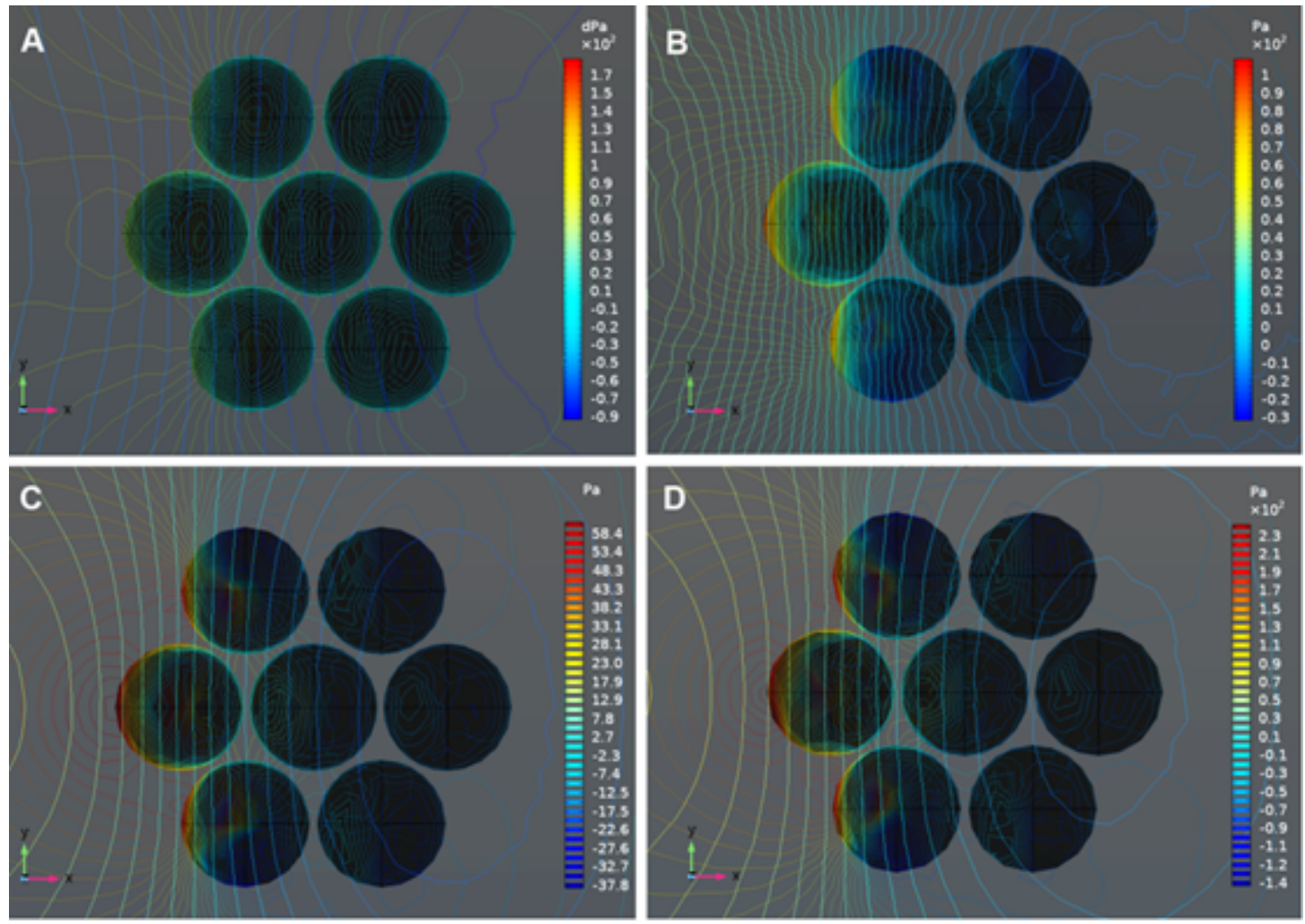


\section{Figure 4}

The 3D pressure fields in the egg cluster model. A-B, laminar flow model act-ing on egg clusters. A, the pressure gradient on the egg cluster $(0.6 \mathrm{~mm}$ in diameter for each egg, $0.03 \mathrm{~mm}$ of the minimum distance among eggs) experienced under a fluid speed of $0.05 \mathrm{~m} / \mathrm{s}$; B, the pressure gradient experienced by the egg cluster under a fluid speed of $0.25 \mathrm{~m} / \mathrm{s}$. C-D, turbulent flow model acting on the clusters. The pressure gradient experienced by the egg cluster under a fluid speed of $0.25 \mathrm{~m} / \mathrm{s}$ (C) and $0.5 \mathrm{~m} / \mathrm{s}$ (D).
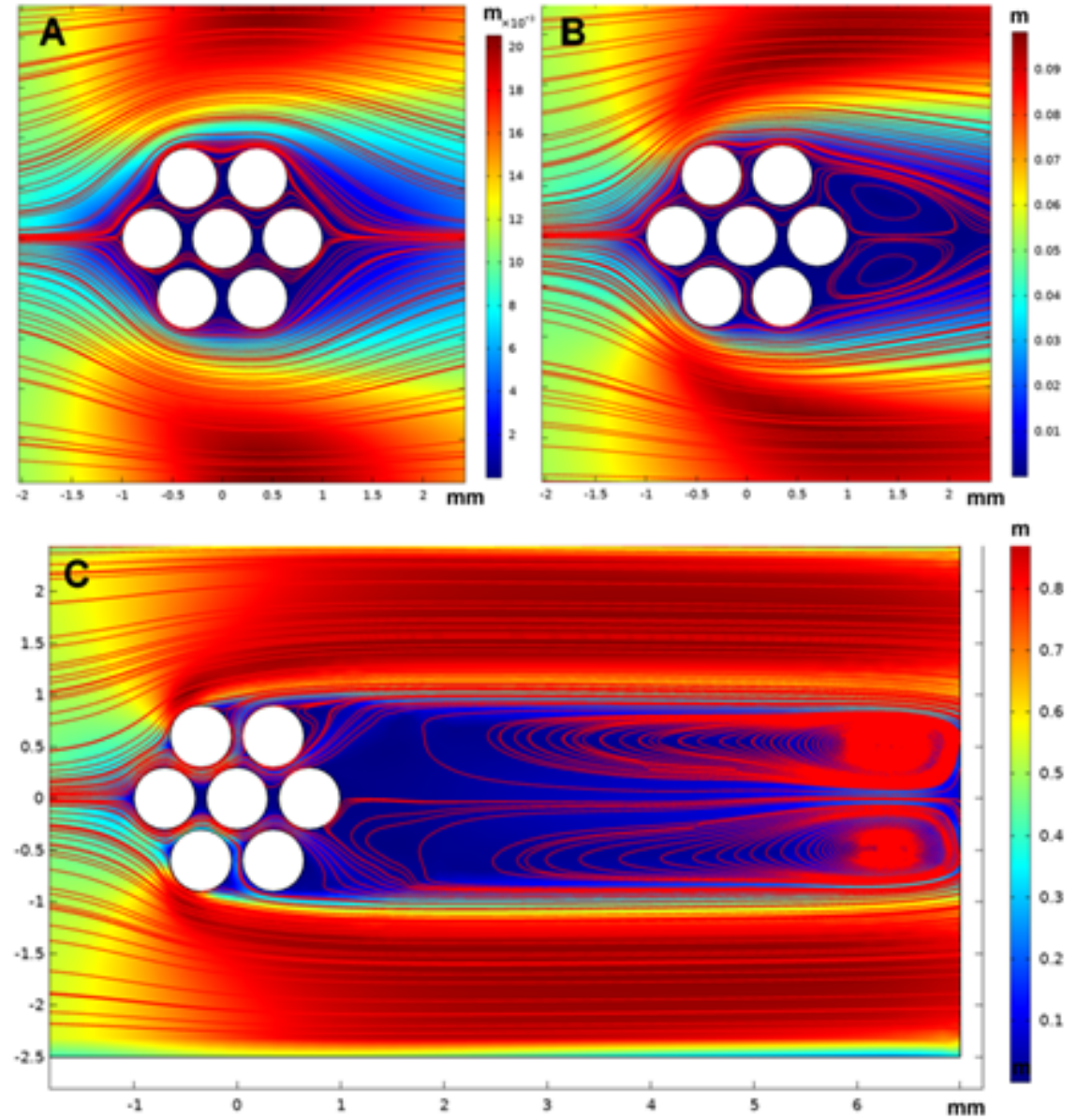

\section{Figure 5}

The egg cluster model under different velocity fields. A-B, laminar flow mod-el. The velocity field experienced by the egg cluster under a fluid speed of $0.01 \mathrm{~m} / \mathrm{s}(\mathrm{A})$ and $0.05 \mathrm{~m} / \mathrm{s}(\mathrm{B}) ; \mathrm{C}$, turbulent flow model, the velocity field experienced by the egg cluster now under a fluid speed of $0.5 \mathrm{~m} / \mathrm{s}$. The different colors represent the velocity field with lower levels in blue and higher in red. 

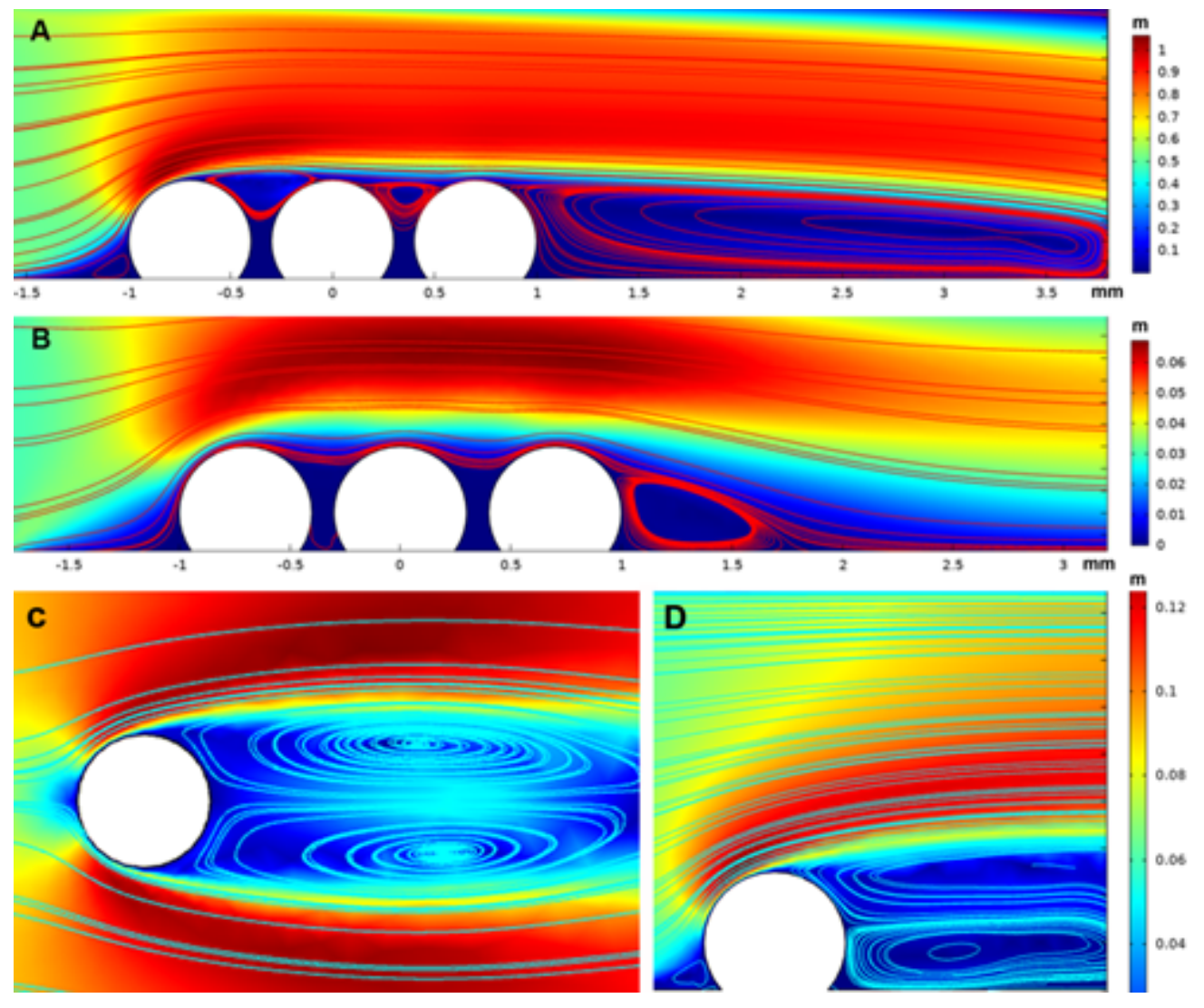

Figure 6

The egg cluster and single egg models under different velocity fields. A, sagittal plane view (turbulent flow model), the velocity field experienced by the egg cluster under a fluid speed of $0.5 \mathrm{~m} / \mathrm{s}$. B, laminar flow model, the velocity field ex-perienced now by the egg cluster under a fluid speed of $0.05 \mathrm{~m} / \mathrm{s}$. C-D, single egg ve-locity field under a laminar flow model, fluid speed is set at $0.05 \mathrm{~m} / \mathrm{s}$; dorsal view represented in (C) and sagittal plane view represented in (D). The different colors represent the velocity field with lower levels in blue and higher in red. 
A
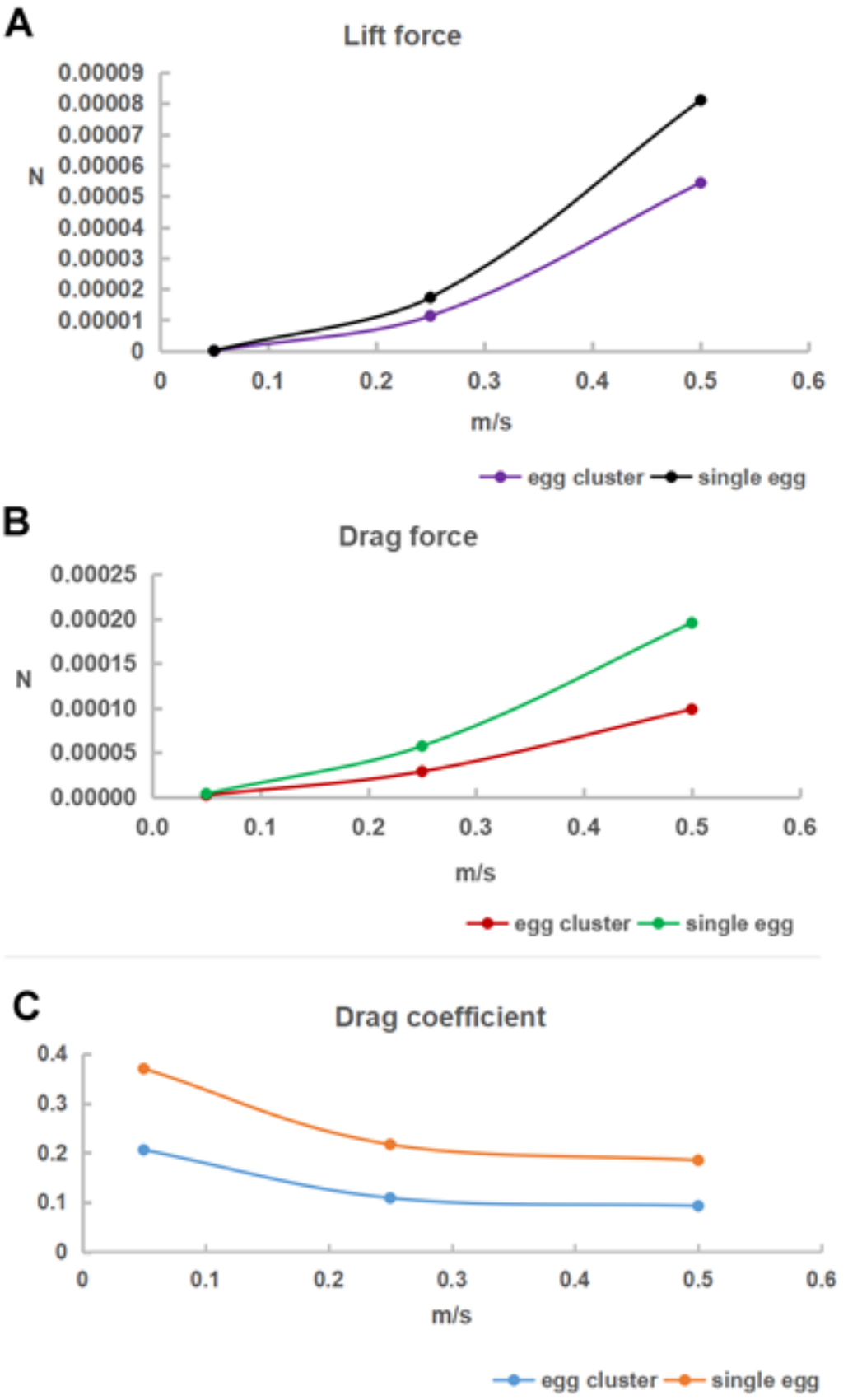

\section{Figure 7}

The current forces and force coefficient of the egg models. Simulation of the egg behavior under different flow regimes. The average lift force (A), the average drag force $(B)$ and the drag coefficient (C) experienced by each egg within the egg cluster and also as individuated cells showing that the average drag and lift force is remarkably reduced on each egg when part of an egg cluster. $\mathrm{X}$ - axis, current speed; $y$ - axis: force $(\mathrm{N})$ or drag coefficient. 